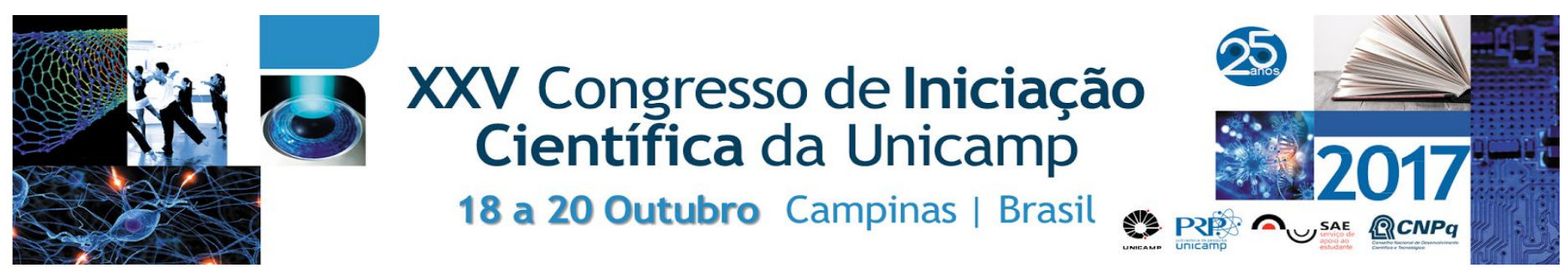

\title{
Implementação de uma Leitora para Sistemas Chipless de RFID Utilizando Técnicas de Rádio Definido por Software
}

\section{Marcos Sei Waiser Junior*, Gilberto T. Santos-Souza, Leonardo L. Bravo-Roger}

\section{Resumo}

O objetivo dessa pesquisa foi realizar contribuições às leitoras de RFID (Identificação por Radiofrequência) para os sistemas que utilizam tags sem chip (chipless RFID tags). Uma nova metodologia para a concepção de leitoras utilizando técnicas de Radio Definido por Software (SDR) foi proposta, permitindo conceber uma plataforma multifuncional reconfigurável capaz de se adequar às diferentes situações decorrentes das diversas aplicações

\section{Palavras-chave:}

RFID, Chipless RFID Reader, SDR.

\section{Introdução}

Hoje em dia os sistemas de RFID são amplamente usados, mas ainda sofrem limitações que afetam seu funcionamento. Por exemplo, o meio ou entorno onde está instalado o sistema interfere no sinal de radiofrequência. $A$ segurança também é uma preocupação nos atuais sistemas de identificação e, obviamente, o custo é uma limitante na massificação dos sistemas. Uma solução para alguns desses problemas são os emergentes sistemas chipless de RFID que, através de ressoadores de diferentes tamanhos, consegue obter uma resposta binária sem que o tag necessite de chip. A contribuição deste projeto foi a de utilizar um kit de SDR programável para a implementação da leitora do sistema chipless de RFID.

\section{Resultados e Discussão}

O front-end de uma leitora chipless de RFID convencional (isto é, utilizando técnicas de Rádio Definido por Hardware) é mostrado na Fig. 1.

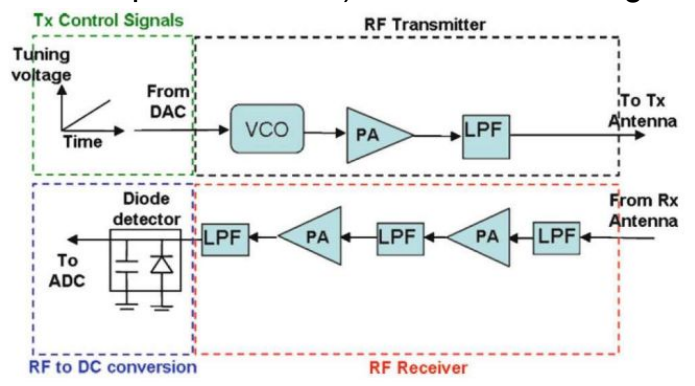

Fig. 1: Front-end de uma leitora chipless de RFID convencional

Para o desenvolvimento da leitora em SDR utilizando o kit Blade RF $x 40$, é possível se basear nesse sistema físico inicialmente para compreender seu funcionamento e, assim, desenvolver um programa que governará o kit de SDR. Primeiramente, entendeu-se o funcionamento do VCO e formas de programá-lo. Observou-se que para a transmissão aplica-se um dente de serra na entrada do VCO e amplifica-se esse sinal na saída. A frequência estabelecida para o projeto foi de 1,5 à $3 \mathrm{GHz}$.Optou-se por programar e testar todos os dados do projeto no software MATLAB, sendo programado em código, pois, assim, conseguiu-se uma oportunidade de personalização maior que verificou ser necessária para o presente projeto.

A Fig. 2 mostra os resultados obtidos no projeto da leitora chipless de RFID em SDR, sendo estes: o sinal do dente de serra, o sinal na saída do VCO e o sinal no domínio da frequência. Verificou-se um comportamento esperado, principalmente no sinal no domínio da frequência, que é o sinal de interrogação proveniente da leitora, mostrando uma amplitude praticamente constante em todo o espectro de frequências, o que é desejado.

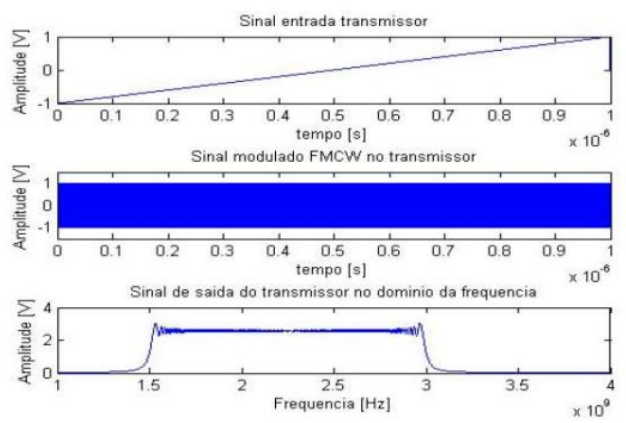

Fig. 2: Leitora chipless de RFID em SDR: sinal dente de serra, sinal de saída do VCO e sinal de interrogação Conclusões

O projeto atingiu seus objetivos, sendo projetado o sinal de interrogação de uma leitora chipless de RFID em SDR. O projeto dessa leitora em SDR trouxe a simplificação de seu hardware tornando seu projeto mais simples e reconfigurável.

\section{Agradecimentos}

Ao PIBIC/SAE pela bolsa, ao Professor Leonardo Bravo-Roger por todo apoio durante o projeto, ao doutorando Gilberto Santos-Souza por todo ensinamento durante o processo e ao Robert Kelvin pela parceria nos projetos. 